\title{
SKELETO-DENTAL CHANGES AFTER CAMOUFLAGE TREATMENT IN CLASS II DIVISION 1 ADULT PATIENTS WITH AVERAGE MANDIBULAR PLANE ANGLE
}

\author{
Dr. Dashrath Kafle', Dr. Zaruba Ulrich² \\ Lecturer, ${ }^{1}$ Kathmandu University School of Medical Sciences \\ Private practice, ${ }^{2}$ Linz, Austria \\ E-mail: dashrath07@yahoo.com
}

\section{ABSTRACT}

Objective: To assess the skeleto-dental changes in adult Class II Division 1 patients with average mandibular plane angle after camouflage orthodontic treatment by premolars extraction. Materials and Method: Total 30 adult female patients, aged between 20-40 years with Class II Division 1 malocclusion with average mandibular plane angle ( Mp-SN: 30-38) were selected for the study. Pre-treatment and post-treatment cephalographs were traced and different measurements are derived from skeletal and dental landmarks. Statistical analysis was done by paired t-test using SPSS software version 16.00. Results: SNA, SNB and ANB angles were reduced significantly. The maxillary length was also decreased significantly. However mandibular dimension was not changed significantly after camouflage treatment. The upper and lower incisors were significantly intruded whereas upper molar was slightly intruded and lower molar was significantly extruded. Antero-posteriorly, incisors were retracted significantly. Upper molars had negligible mesial movement however lower molars had moved mesially with statistical significance. Conclusion: During camouflage treatment care should be taken on incisor retraction. The vertical control of the molar teeth is important during the treatment period to avoid worsening of the facial proportion.

Key words: Angle Class II Division 1, Camouflage, Mandibular plane angle, Skeleto-dental

\section{INTRODUCTION}

Class II malocclusion or disto-occlusion is the second most common malocclusion in the world. The most commonly followed treatment regimen for Class II malocclusion is extraction of upper first premolars with or without lower premolars extraction; and the most frequent debate in the orthodontic history till today is extraction versus nonextraction. Though the growth modification of the skeletal malocclusion is somehow possible in adolescents, the comprehensive orthodontic treatment of Class II Division 1 malocclusion in adults are routinely carried out by camouflage treatment.

Pre-Tweed era was almost dominated by non-extraction philosophy propagated by his mentor Sir E.H. Angle. Angle is believed to be influenced by the philosophy of Rousseau who emphasized on the perfectibility of man. Angle thought that if teeth were placed in proper occlusion, the bone will grow in the new position of teeth and will be stabilised eventually. Though this hypothesis was so convincing during Angle time, it is invalid now. Later Tweed and Begg philosophy influenced the orthodontic world during the mid and late twentieth century so much that extraction treatment was regular cook book for most of the orthodontists. At present non-extraction trend is on its extreme end. There is decline in extraction treatment since the end of the twentieth century. The recent trend for non-extraction may be due to the use of bonded appliances, introduction of the distalization appliances and probably due to changing perception of aesthetics. At present fuller profile is preferred than straight or flat profile preferred in the past sixties or seventies decade. ${ }^{4}$

Some clinicians claim that extraction therapy reduces the vertical dimension of the face which leads to TMJ problem and others also propose that over-retraction of the anterior teeth cause the posterior positioning of the condyle ultimately leading to temporomandibular joint dysfunction. Both hypotheses have been refuted so far. In contemporary orthodontics, extraction and non extraction decision is not 
and should not be influenced by any belief or philosophy without sound evidence. The best decision should be done in favour of the patients with the consideration of aesthetics, stability and function. The aim of our study is to compare the dento-skeletal changes in average angled adult female patients with Class II Division 1 malocclusion after orthodontic treatment.

\section{MATERIALS AND METHOD}

This prospective study is done on 30 adult female patients of age 20 years to 4 o years. All the patients were treated with upper and lower premolar extraction with same treatment philosophy i.e. preadjusted edgewise appliance with MBT prescription; 0.022 " slot size brackets were used. The extraction space was closed by sliding mechanics. Class II elastics were used when necessary to bring the canine and molar relation into Class I. The opening of the bite was usually done with the reverse/accentuated curve of Spee incorporated into the arch wires.

The criteria set for patient selection were; having Class II Division 1 malocclusion with over jet $>5 \mathrm{~mm}$, medium plane angle (MP-SN Angle 30-38 ), Skeletal Class II malocclusion (ANB >5 degree), having clear pre and post treatment lateral cephalogram and dental cast.

Patients treated with functional appliance, head gear or temporary anchorage devices (TAD) were not included in the study. In some cases transpalatal arches were used for the anchorage purpose.

The lateral cephalogram was taken pre and post treatment by the same machine with same guideline. The lateral ceph was traced manually by one of the investigators and checked by another. To determine the intra observer error, the 10 radiographs were randomly selected two weeks later and re-traced by the same investigator. Dahlberg's formula $\mathrm{E}=\mathrm{vd}^{2} / 2 \mathrm{n}$ was used to calculate the measurement error. The error for linear measurement was averaged to be 0.5 $\mathrm{mm}$ and angular measurement $0.5^{0}$.

Following landmarks (Figure 1) were identified on the lateral cephalogram depending on the criteria described in the literature:

S-sella, N-nasion, Ar-articulare, A-point A, B-point B, Me-menton,Gn-gnathion, Go- gonion, ANS- anterior nasal spine, ANS'- perpendicular dropped on the palatal plane from point A, PNS- posterior nasal spine, X- Pterygomaxillary fissure, UIE- tip of the crown of the upper incisor, UIAroot apex of the upper incisor, LIE- crown tip of the lower incisor, LIA- root apex of the lower incisor, TUM- tip of the mesiobuccal cusp of upper first molar, TLM- tip of the mesiobuccal cusp of lower first molar, Ms- mesial surface of the upper first molar crown, Mi- mesial surface of the lower first molar crown. CFH plane - SN plane rotated clockwise 7 degrees. FHp-The perpendicular line dropped to the $\mathrm{CFH}$ passing through the S. PP- Palatal plane, constructed by joining ANS to X, Mxp- the perpendicular line on the palatal plane passing through S, OP1- plane joining the tip of the mesio buccal cusp of maxillary first molar and tip of the crown of the upper central incisor. OP2- Plane joining the tip of the mesiobuccal cusp of the lower first molar and the tip of the lower central incisor crown.

Out of those landmarks; following angular and linear skeletodental values were derived:

SNA $\left({ }^{\circ}\right), \mathrm{SNB}\left({ }^{\circ}\right), \mathrm{ANB}\left({ }^{\circ}\right), \mathrm{A}-\mathrm{FHp}(\mathrm{mm}), \mathrm{PP}-\mathrm{SN}\left({ }^{\circ}\right)$, MP$\mathrm{SN}\left({ }^{\circ}\right)$, PP-MP $\left(^{\circ}\right)$, N-Me (mm), ANS'-Me (mm), ANS'$\mathrm{Me} / \mathrm{N}-\mathrm{Me}$, S-Go mm), Go-Mxp (mm), Go-Mxp/S-Go, (ANS-FHp)-(X-FHp) (mm), Ar-Gn (mm), Ar-Go (mm), UI-NA $\left(^{\circ}\right)$, UI-CFH $\left(^{\circ}\right)$, UIE-NA (mm) UIE-FHp (mm), UIE-PP (mm), MS-FHp (mm), TUM-PP (mm), LI-NB $\left(^{\circ}\right)$, L1-MP $\left(^{\circ}\right)$, LI-NB (mm), LIE-NB (mm), LIE-FHp (mm), LIE-MP (mm), MI-FHp (mm), TLM-MP (mm), OJ (mm), OB (mm), OP1-CFH $\left(^{\circ}\right)$, OP1-PP $\left(^{\circ}\right)$, OP2-CFH $\left(^{\circ}\right)$, OP2$\mathrm{MP}\left({ }^{\mathrm{O}}\right)$.

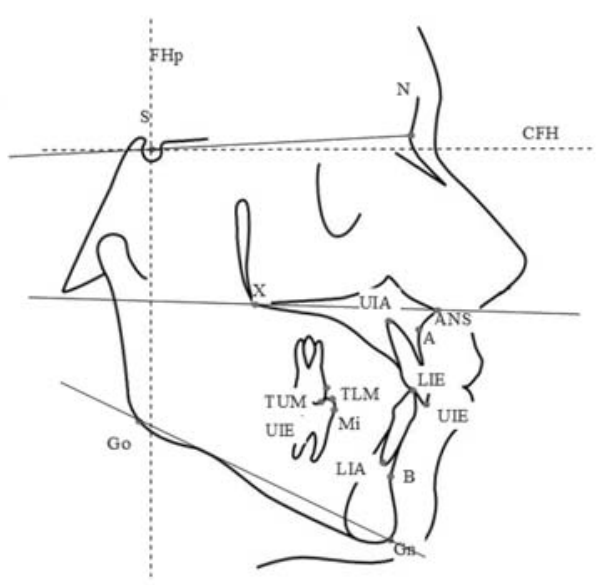

Fig: 1 Cephalometric landmarks 


\section{STATISTICAL ANALYSIS}

The data were collected in excel sheet and later transferred into the SPSS software for statistical analysis. The pre treatment and post treatment values were compared by paired $t$ test. The lowest $\mathrm{p}$ value for the statistical significance was set to be at 0.05 .

\section{RESULTS}

The comparison of pre-treatment and post treatment skeletodental changes is shown in Table 1 and 2. There is significant change in maxillary base (SNA, ANB) after treatment. There are significant changes in maxillary dental parameters \{U1NA (mm,), U1-CFH, UIE-FHp $\}$ before and after treatment. However the antero-posterior position of the upper molar is not changed after treatment. The maxillary length (ANSFHp)-(X-FHp) is decreased in adult group by $0.73 \mathrm{~mm}$ which is statistically significant $(p=0.00)$. The SNB angle is significantly decreased after treatment. The linear measurements representing mandibular dimension (Ar-Go, S-Go, Ar-Gn, Go-Gn) are not changed after treatment. Antero-posteriorly, lower incisor is moved significantly distally (L1-NB, LIE-FHp) after the treatment. There is significant mesial movement of lower molars after the treatment that is $2.41 \mathrm{~mm}(\mathrm{p}=0.02)$.

The results on vertical dimension do not show much significant changes except for few parameters. There is significant extrusion of upper central incisor (UIE-PP) where as slight amount of intrusion of upper first molar is seen $(0.07 \mathrm{~mm})$ which is not statistically significant. There is significant intrusion (LIE-MP) of the lower incisors and extrusion of the lower first molars (TLM-MP) after treatment. The amount of overbite reduction is also significant after treatment.

The skeletal plane angles (MP-SN, PP-SN, and PP-MP) are not affected by treatment however the plane angles dependent on occlusion are significantly altered after treatment.

\section{Table 1: Skeletal changes before and after orthodontic treatment}

\begin{tabular}{|c|c|c|c|c|c|c|}
\hline \multirow{2}{*}{ Measurement } & & & & & \multirow{2}{*}{$\mathbf{P}$} & \multirow{2}{*}{ Significance } \\
\hline & Pre X & \pm SD & Post-X & \pm SD & & \\
\hline SNA ( $\left.{ }^{\circ}\right)$ & 83.02 & 3.39 & 81.17 & 2.96 & 0.00 & $* *$ \\
\hline SNB $\left({ }^{\circ}\right)$ & 75.17 & 3.26 & 74.15 & 3.38 & 0.00 & $* *$ \\
\hline ANB $\left(^{\circ}\right)$ & 7.85 & 1.54 & 7.02 & 1.65 & 0.00 & $* *$ \\
\hline A-FHp (mm) & 64.68 & 3.73 & 62.34 & 4.20 & 0.00 & $* *$ \\
\hline PP-SN (O) & 4.95 & 4.21 & 6.00 & 4.18 & 0.17 & NS \\
\hline MP-SN $\left(^{\circ}\right)$ & 31.88 & 7.10 & 32.94 & 6.43 & 0.21 & NS \\
\hline PP-MP ( $\left.{ }^{\circ}\right)$ & 26.93 & 6.86 & 26.94 & 6.94 & 0.96 & NS \\
\hline $\mathrm{N}-\mathrm{Me}(\mathrm{mm})$ & 115.93 & 6.33 & 116.47 & 6.10 & 0.07 & NS \\
\hline $\mathrm{ANS}^{\prime}-\mathrm{Me}(\mathrm{mm})$ & 63.91 & 5.08 & 64.18 & 5.17 & 0.25 & NS \\
\hline ANS'- Me / N-Me & 0.55 & 0.02 & 0.555 & 0.02 & 0.86 & NS \\
\hline S-Go (mm) & 72.82 & 4.01 & 72.78 & 4.06 & 0.89 & NS \\
\hline Go-Mxp (mm) & 32.22 & 3.45 & 32.17 & 3.60 & 0.77 & NS \\
\hline Go-Mxp / S-Go & 0.44 & 0.03 & 0.44 & 0.04 & 0.81 & NS \\
\hline (ANS-FHp) - (X-FHp) (mm) & 51.52 & 3.19 & 50.79 & 2.87 & 0.01 & $*$ \\
\hline $\operatorname{Ar}-\mathrm{Gn}(\mathrm{mm})$ & 97.23 & 4.11 & 96.97 & 4.13 & 0.33 & NS \\
\hline Go-Gn (mm) & 67.89 & 4.09 & 68.00 & 3.73 & 0.67 & NS \\
\hline $\operatorname{Ar}-\mathrm{Go}(\mathrm{mm})$ & 43.13 & 3.28 & 42.78 & 3.27 & 0.34 & NS \\
\hline
\end{tabular}

${ }^{*} P<0.05 * * P<0.01$ 


\begin{tabular}{|c|c|c|c|c|c|c|}
\hline \multirow{2}{*}{ Measurement } & \multicolumn{4}{|c|}{ Adult } & \multirow{2}{*}{$\mathbf{P}$} & \multirow{2}{*}{ Significance } \\
\hline & Pre $X$ & $\pm S D$ & Post-X & $\pm \mathrm{SD}$ & & \\
\hline$+1-\mathrm{NA}\left({ }^{\circ}\right)$ & 30.00 & 6.69 & 14.75 & 6.21 & 0.00 & $* *$ \\
\hline$+1-\mathrm{CFH}\left({ }^{\mathrm{O}}\right)$ & 124.52 & 7.00 & 106.74 & 6.89 & 0.00 & $* *$ \\
\hline UIE-NA (mm) & 4.49 & 2.15 & 0.06 & 1.90 & 0.00 & $* *$ \\
\hline UIE- FHp (mm) & 70.86 & 4.65 & 63.21 & 5.82 & 0.00 & $* *$ \\
\hline UIE- PP (mm) & 29.19 & 3.45 & 30.22 & 3.64 & 0.00 & $* *$ \\
\hline Ms- FHp (mm) & 42.60 & 4.62 & 42.38 & 4.86 & 0.86 & NS \\
\hline TUM- PP (mm) & 23.85 & 2.50 & 23.78 & 2.22 & 0.68 & NS \\
\hline$-1-\mathrm{NB}\left({ }^{\circ}\right)$ & 31.09 & 6.74 & 31.94 & 4.51 & 0.50 & NS \\
\hline$-1-M P\left({ }^{\circ}\right)$ & 98.70 & 6.77 & 100.06 & 5.22 & 0.25 & NS \\
\hline LIE- NB(mm) & 8.24 & 2.63 & 7.08 & 2.08 & 0.00 & $* *$ \\
\hline LIE- FHp(mm) & 63.59 & 4.46 & 60.42 & 5.53 & 0.00 & $* *$ \\
\hline LIE-MP(mm) & 39.89 & 2.73 & 37.02 & 3.49 & 0.00 & $* *$ \\
\hline Mi- FHp $(m m)$ & 40.36 & 4.95 & 42.77 & 5.38 & 0.02 & $*$ \\
\hline TLM- MP (mm) & 29.49 & 2.33 & 30.74 & 2.49 & 0.00 & $* *$ \\
\hline $\mathrm{OJ}(\mathrm{mm})$ & 7.26 & 1.72 & 2.79 & 0.76 & 0.00 & $* *$ \\
\hline $\mathrm{OB}(\mathrm{mm})$ & 4.47 & 1.68 & 3.18 & 0.85 & 0.00 & $* *$ \\
\hline (Mi- FHp)-(Ms- FHp)(mm) & -2.24 & 0.73 & 0.39 & 0.88 & 0.00 & $* *$ \\
\hline OP1 - CFH (O) & 8.55 & 4.94 & 14.58 & 5.17 & 0.00 & $* *$ \\
\hline OP1- PP $\left({ }^{\circ}\right)$ & 9.60 & 3.70 & 14.58 & 4.82 & 0.00 & $* *$ \\
\hline OP2- $\mathrm{CFH}\left({ }^{\circ}\right)$ & 1.43 & 6.98 & 8.88 & 6.24 & 0.00 & $* *$ \\
\hline $\mathrm{OP} 2-\mathrm{MP}\left({ }^{\mathrm{O}}\right)$ & 24.45 & 5.63 & 18.07 & 6.06 & 0.00 & $* *$ \\
\hline
\end{tabular}

${ }^{*} P<0.05 * * P<0.01$

\section{DISCUSSION}

Our study was aimed to find the effect of orthodontic treatment in adult patients with extraction therapy. It is obvious that, adult patients possess negligible growth. The effect of orthodontic treatment in maxilla as seen in our study is decrease in SNA angle and remodelling of point A. The study of Dyer et al showed significant reduction of maxillary length in both adolescent and adult samples. Their findings in adult sample are similar to the findings of our study. Ricketts has suspected that the vigorous retraction of the teeth particularly parallel to the axes of the roots prevent the forward growth of the maxilla in adolescents. The treatment change in SNA angle and point A is similar in our study compared to Dyer's, Harris's and Vaden's study. The sagittal position of the maxillary first molars is not changed as the maximum effort was applied to preserve the anchorage. The maximum retraction of upper anterior teeth is done to camouflage the skeletal class II problem which is evidenced by decrease in U1-NA $\left(\mathrm{mm}\right.$ and $\left.{ }^{\circ}\right), \mathrm{U} 1-\mathrm{CFH}\left(^{\circ}\right)$ and UIEFHp (mm).

As shown in some studies, there is increased chance of incisor over retraction in adults whereas in adolescents this is not the problem. The present study also found the similar result. It is obvious from our result that incisors are intruded and retracted significantly at the end of the treatment. This may lead to the increased chance of external apical root resorption as pointed by Graber. ${ }^{13}$

During the treatment of Class II malocclusion, the Class II inter arch elastics are usually part of the treatment. Though 
they bring the occlusion into better interdigitation, the unavoidable side effect of Class II elastics are lower molar and upper incisor extrusion. This extrusive mechanics cants the occlusal plane which can be seen in our study too. It is pointed out by some authors that the increased steepness of the occlusal plane autorotates the mandible, which makes the facial profile more convex, increasing the vertical height of the anterior face. However our study does not support this statement. The lack of vertical height increase in our study may be due to the wedge effect by the mesial movement of the molars.

\section{CONCLUSION}

While treating the adult patients, we should always be cautious not to lose the vertical control of the teeth. The Class II elastic in adults should be used very cautiously if needed. The over retraction of the anterior teeth should always be done judiciously to prevent root resorption.

\section{REFERENCES}

1 AST DB CJCN. The prevalence and characteristics of malocclusion among senior high school students in upstate New York. Am J Orthod $1965 ;(51): 437-45$.

2 Massler M and J.M.Frankel. Prevalence of Malocclusion in Children Aged 14 to 18 years. Am J Orthod 1951;37:751-68.

3 Martins MG, Lima KC. Prevalence of malocclusions in 10- to 12-year-old schoolchildren in Ceara, Brazil. Oral Health Prev Dent 2009;7(3):21723.

4 Profitt WR. Orthodontic treatment planning-Limitations, Controversies and special problems. Contemporary orthodontics. 4 th ed. Elsevier Science; 2007. p. 268-330.

5 Sadowsky C, Begole EA. Long-term status of temporomandibular joint function and functional occlusion after orthodontic treatment. Am $J$ Orthod 1980 Aug;78(2):201-12.

6 Luecke PE, III, Johnston LE, Jr. The effect of maxillary first premolar extraction and incisor retraction on mandibular position: testing the central dogma of "functional orthodontics". Am J Orthod Dentofacial Orthop 1992 Jan;101(1):4-12.

7 Rendell JK, Norton LA, Gay T. Orthodontic treatment and temporomandibular joint disorders. Am J Orthod Dentofacial Orthop 1992 Jan; 101(1):84-7.

8 Hirata RH, Heft MW, Hernandez B, King GJ. Longitudinal study of signs of temporomandibular disorders (TMD) in orthodontically treated and nontreated groups. Am J Orthod Dentofacial Orthop 1992 Jan;101(1):35-40.

9 Dyer GS, Harris EF, Vaden JL. Age effects on orthodontic treatment: adolescents contrasted with adults. Am J Orthod Dentofacial Orthop 1991 Dec;100(6):523-30.

10 Ricketts RM. The influence of orthodontic treatment on facial growth and development. Angle Orthod 1960;(30):103-33.

11 Harris EF, Dyer GS, Vaden JL. Age effects on orthodontic treatment: skeletodental assessments from the Johnston analysis. Am J Orthod Dentofacial Orthop 1991 Dec;100(6):531-6.

12 Vaden JL, Harris EF, Behrents RG. Adult versus adolescent Class II correction: a comparison. Am J Orthod Dentofacial Orthop 1995 Jun;107(6):65161.

13 Graber TM. Orthodontics principles and practice. 3rd ed. WB Saunders: 1972.

14 Melsen B. Adult orthodontics: factors differentiating the selection of biomechanics in growing and adult individuals. Int J Adult Orthodon Orthognath Surg 1988;3(3):167-77.

15 Dermaut LR, Beerden L. The effects of class II elastic force on a dry skull measured by holographic interferometry. Am J Orthod 1981 Mar;79(3):296304.

16 Fushima K, Kitamura Y, Mita H, Sato S, Suzuki Y, Kim YH. Significance of the cant of the posterior occlusal plane in class II division 1 malocclusions. Eur J Orthod 1996 Feb;18(1):27-40.

17 Schuddy FF. The rotation of the mandible resulting from growth: Its implications in orthodontic treatment. Angle Orthod 1965;Jan(35):36-50. 